\title{
Erratum to: Podocyturia is significantly elevated in untreated vs treated Fabry adult patients
}

Hernán Trimarchi ${ }^{1,6} \cdot$ Romina Canzonieri $^{2} \cdot$ Amalia Schiel $^{2} \cdot$ Juan Politei $^{3}$. Aníbal Stern ${ }^{2} \cdot$ José Andrews $^{1} \cdot$ Matías Paulero $^{1} \cdot$ Tatiana Rengel $^{1}$. Alicia Aráoz ${ }^{4} \cdot$ Mariano Forrester $^{1} \cdot$ Fernando Lombi $^{1} \cdot$ Vanesa Pomeranz $^{1}$. Romina Iriarte $^{1} \cdot$ Pablo Young ${ }^{5} \cdot$ Alexis Muryan $^{2} \cdot$ Elsa Zotta $^{4}$

Published online: 25 March 2016

(C) Italian Society of Nephrology 2016

\section{Erratum to: J Nephrol}

DOI 10.1007/s40620-016-0271-z

Unfortunately, the online published article has errors in Table 3. The correct table is given in the following page.

The online version of the original article can be found under doi:10.1007/s40620-016-0271-z.

Hernán Trimarchi

htrimarchi@hotmail.com

1 Nephrology, Hospital Británico de Buenos Aires,

Buenos Aires, Argentina

2 Biochemistry Services, Hospital Británico de Buenos Aires, Buenos Aires, Argentina

3 Neurology Department, Fundación para el Estudio de las Enfermedades Metabólicas FESEN, Buenos Aires, Argentina

4 IFIBIO Houssay, UBA CONICET Facultad de Medicina, Universidad de Buenos Aires, Buenos Aires, Argentina

5 Internal Medicine, Hospital Británico de Buenos Aires, Buenos Aires, Argentina

6 Servicio de Nefrología, Hospital Británico de Buenos Aires, Perdriel 74, 1280 Buenos Aires, Argentina 
Table 3 Comparison of different variables between untreated and treated Fabry patients

\begin{tabular}{lllr}
\hline Variables & Group 2A & Group 2B & P \\
\hline Age (years) & $29(16-74)$ & $43(18-65)$ & 0.0614 \\
$\begin{array}{l}\text { Duration of enzyme replacement } \\
\quad \text { therapy (months) }\end{array}$ & 0 & $40.1(29-55)$ & $<0.0001$ \\
Serum creatinine (mg/dl) & $0.62(0.47-1.10)$ & $1.24(0.48-12.50)$ \\
CKD-EPI (ml/min) & $95.54(55.30-101)$ & $59.12(4.87-135)$ & 0.0049 \\
Proteinuria $(\mathrm{gr} / 24 \mathrm{~h})$ & $0.10(0.04-1)$ & $0.66(0.04-4.20)$ & 0.0057 \\
Podocyte count $(\mathrm{cells})$ & $1.48(0.20-6.84)$ & $3.35(1-18.60)$ & 0.0008 \\
Podocytes/100 ml urine & $7.65(1-34.20)$ & $50.30(8-235.60)$ & 0.0006 \\
Podocytes/gr urinary creatinine & $129.10(15.70-910.30)$ & D33G; C281; C801; C1244T; \\
Mutations & D33G; C281; C801; & T194I; L180F; L415P; D155H \\
\hline
\end{tabular}

